\title{
As Competências do Professor de Educação Física na Pós-modernidade
}

EuniceHelenaTamiossoVega*

\section{Resumo}

Esteartigo, resultante dadissertaçãodeMestradoem Educação, apresentadanaPontificia Universidade $\mathrm{Ca}$ tólicadoRio Grande doSul(PUCRS) em 2002, apresentaascompetênciasdoprofessorde EducaçãoFísica napós-modemidade.Apesquisarealizou-seapartirde entrevistasemi-estruturadacomparticipantesdeduas Instituições de Ensino Superior, uma pública eoutra privada, possibilitandoumaaproximaçãodessas realidades. Naanálise das entrevistas emergiramascompetênciaspessoal,profissionale social, integrandoumestudomaisamplo, que compreendeasteorias educacionais. Asconclusões dapesquisa remetemàavaliação críticadas competênciasbásicasqueformamumconjunto de ações que expressamo atual significado da EducaçãoFísicanocontextoeducacionale social.

Palavras-chave: competências, pós-modernidade, desenvolvimentohumano.

\section{Abstract}

This article, resulting from the dissertation of Master Degree in Education submitted to the Catholic University of Rio Grande do Sul(PUCRS) in 2002, presents the competences of the physical-education teachers in the post-modernity. This research began after semi-structured interviews applied to students fromtwo different university schools-apublic and aprivateone-allowing the approach to these realities. Personal,professional and social compe-tence arose from the analysis of these interviews, integrating a wider study including the educational theories. The research conclusions lead to a critical evaluation of the basic competences included in a set of actions expressing the curentmeaning of PhysicalEducation withing the educational and social context.

Keywords: competences, post-modernity, human development.

\section{Resumen}

Este artículo, resultado de la disertación de Maestría en Educación presentada en la Pontifícia Universidade Católica do Rio Grande do Sul,-PUCRS (UniversidadCatólica de Rio Grande del Sul, Brasil) - en 2002, presenta las competencias del profesorde Edicación Física en la postmodernidad. La investigación se realizó a partir de entrevistas semiestructuradas con participantes de dos instituciones de Educación Superior-una pública yotra privada-que permitieron la aproximación a esas realidades. Del análisis de las entrevistas surgieron la competencia personal, la profesional y la social, integrando un estudio más amplio, que abarca lasteorías educacionales. Las conclusiones de la investigación conducen a la evaluación críticade las competencias básicas que forman unconjuntode acciones que expresanel significadoactual de la Educación Física dentro del contexto educacionaly social.

Palabras-clave: competencias, postmodernidad, desarollohumano.

\section{Introdução}

Napós-modemidadeestãosendodesenvolvidashabilidadesparapensareescolhercaminhosaserempercomidos paraaevoluçãofutura, atravésdaexperiênciadainvesti- 
gação, doquestionamentoedareflexão,comumaideologiabaseadanaimagemdeumnovomundo.Ummundodeincertezaseinacabado,ondeaconsciênciacorporal passapelanecessidadedemanterumasaúdeequilibrada, fundamental paracomporonovoserhumanoquetende apossuirmaiores cuidados comaeducaçãodocorpoe dosrelacionamentos, criandoassim, umsensodesignificado, queteminícionas aulasdeEducaçãoFísica. No permanenteestudododesenvolvimentohumano,considera-sefundamentalqueo/aprofessor/atenhaumaautoimagemboaeaauto-estimaequilibradaparaquepossa desenvolversuascompetências.

Abuscadeumaidentidadeprofissional própriasempre esteveemfoconestepercurso,mascompoucoêxito, visto queadisciplinadeEducaçãoFísicaquaseficouexcluída daúltimaLeideDiretrizeseBases,porserjulgadadesnecessáriaaocumículoescolareque, graçasaumprojetode leiapresentado,foireconsideradacomoessencial.Diante daobservaçãodequeoprincipal problemadaEducação Físicaresideemumaordemepistemológica, presenteem umavisãolimitadadoprocessoeducacional esocial,me propusaelaborarumapesquisaqueapontasseascompetências básicasqued/aprofessor/adeEducaçãoFísicadeve possuirparaatuarnesseprocesso.Adinâmicadomundo internoaconteceeminteraçãocomomundoexternoe, juntos, revelamasemoções, reflexões, decisõeseações, queformamassinergiasdasaçõesespontâneas.Compreendercomoaconteceessainterdependênciaquemoveo serhumano, toma-sefundamental paraentenderasnovascompetências.

OobjetivoprincipalfoiestudarascompetênciasdosprofessoresdeEducaçãoFísicanapós-modemidadeemduas InstituiçõesdeEnsinoSuperior,umapúblicaeoutraprivada, eas basesepistemológicas doseuconhecimento, possibilitandooentendimentodestascompetências, bem comodassuasatuaçõesem sociedade, maisespecificamente,nasociedadeeducacional. Tal problemasurgiu danecessidadedereverquecompetênciassãoessas,eisso pôdeserfeitopelareflexãodocorpodocentesobreoseu própriofazer,desencadeandoumprocessodetransformação.Esteestudo, baseadonalinhadepesquisadaPessoae doDesenvolvimentohumano, sepreocupouemdeixar
claroascompetênciasideaisdosprofessoresdeEducação Física, atravésdoestudodapós-modemidade,queilustra ahistóriadaEducaçãoFísicaesugerequeascompetênciasquehojeseexigedosprofessoressejamreconfiguradas paraestemomentohistóricoimportante.

Optei por quatrocampos temáticosque, a meu ver, apontamparaumaargumentaçãocomcoerênciainterna, que são: as considerações sobre a pósmodemidade; umbrevehistóricodaEducaçãoFísica noBrasil;o/aprofessor/adeEducaçãoFísicaeseudesenvolvimento; eascompetências do/aprofessor/ade EducaçãoFísicanapós-modemidade.

A pós-modemidadeestásendo vistacomoumaciência contemporânea, imbuída de criatividade e indeterminismo,combinandoocientíficocomoestético. Naopiniãode Doll(1997,p. 19), isso aindanão estáclaroparatodaacomunidadecientífica:

\section{Asimplicações de umaperspectivapós-modernaparaa educação e o currículo são imensas, mas de forma al- guma claras. [...] Na verdade, o que acontece é que surge um senso de ordem inteiramente novo: não a ordemsimétrica, simplese e eqüencial que a Ciênciaclás- sica tomou emprestada do pensamentomedieval, mas uma ordem assimétrica, caótica efractal, que estamos começandoadescobrirnas Ciências pós-modernas.}

AEducaçãoFísica, portrazerumaherançadotecnicismonoseudesenvolvimento, levaalguns professoresa teremsuaatuaçãobaseadaem práticas ultrapassadas. Paraentenderestasmudançasfoinecessárioorganizar umbrevehistóricodaEducaçãoFísicanoBrasil,onde sebuscoucompreenderasuahistoricidade, oquesignificaavançarcombasessólidasnumoaodesenvolvimento socialecultural, trazendoinformaçõesimportantesdeste processo.Noreferencial teóricodo/aprofessor/aeseu desenvolvimento,sãoenfocadasquestõespertinentesao conhecimentodasindividualidadespessoais, dainteligênciafísico-cinestésica, bemcomoascrisesqueosdocenteseasinstituições educacionaisestãopassando.E, porúltimo, foifeitoumensaiosobreascompetências do/aprofessor/adeEducaçãoFísica, formandooeixo principaldesteestudo,atravésdoqualnosmovemospara compreenderoconjuntodeações pedagógicasqueo/a 
professor/apossuinapós-modemidadeequesepretendeestaremcontempladasnestapesquisa.Essascompetências, quandobemdesenvolvidas, darãoosuportenecessárioparacontornaras situações problemáticasque surgemaolongodavida.

\section{Metodologia}

Estapesquisaédecunhoqualitativo,emníveldescritivo,epretendeuapontarascompetênciasdosprofessores deEducaçãoFísica, atravésdostestemunhosdosprópriosdocentes. Estametodologiapermitiuregistrardados subjetivos dosentrevistadosecontribuiu paradiminuir adistânciaentreo conhecimentocientíficoadquirido comasteorias daeducaçãoeas teorias referentesàculturadomovimentohumano. Assim, observeiqueasteoriasdaEducaçãoFísica, porvezesficamescondidasnas práticasdesportivas,sendoimpedidasdetornarem-seum referencial teórico de açãoeducativa. Paraa coletae análise de dados foi utilizada a entrevista semiestruturada,eométodoempregadofoiaAnálisedeConteúdo. Asentrevistasforam gravadas, transcritasnaíntegraedevolvidasaosprofessoresparaajustesnecessários,favorecendoassimaexplicaçãoeacompreensãoda totalidadedainvestigação, além da descriçãodofenômenosocial dapós-modemidade,quesugerequesedê retorno, poisumarealidade, aoserquestionada, provocareflexões, eistofoi sentidoatravésdadevoluçãodas transcrições, algumaspessoalmente, outras, viacomeio eletrônico.Paraquenãohouvesseaidentificaçãodos participantesnorelatóriodepesquisafoi-lhes dadoos númerosdeuma seis para os docentes dainstituição privadaede seteadoze paraos docentes dainstituição pública. Estetrabalhodeinterpretaçãolevou-meaelaboraçãode umcapítuloondedescrevoeinterpretoos resultadosextraídosdaanálise.

\section{Relatando e interpretando os dados}

Foramencontradas três grandes categorias denominadas:competênciapessoal,competênciaprofissional
ecompetênciasocial.Nacompetênciapessoal, vimos comosubcategorias: visãoda corporalidade; visãoda corporeidade; vivênciaesportiva; evisãoholística. $\mathrm{Na}$ competênciaprofissional: experiênciasdidático-pedagógicas; multidisciplinaridade; interdisciplinaridade; ecrises (naIES, nafaculdade deEducaçãoFísicaena escola). Nacompetênciasocial: pesquisas sociais; InstituiçãodeEnsinoSuperior(IES)e sociedade-diálogo/troca/reflexo; devolução; epublicações.

Aabordagemdascompetênciasdeur-senosentidodeapontarumconjuntodeações, consideradascomoasqualificaçõesqueosprofessoresdeEducaçãoFísicapossuemna suaatuação.Porserumaáreaquetrabalhacomomovimentohumano, elavolta-separaconhecimentosrelacionadosàsquestõespessoais, profissionaise sociaisdeformapeculiar.Nessastrêscompetências, encontram-sereferênciasquesinalizameste/aprofessor/a, vistoqueele/a interagenostrêsníveis, eestescaminhossãopermeados poressasações,quetambémdenominamoscompetênciascomosinônimodeaptidões.

\section{Competência pessoal}

Juntamentecomas duasoutrascategoniasencontradasneste estudo-competência profissionalecompetênciasocial,formaa base doprofissional que atua na pósmodemidade.Enten-
Acompetênciapessoalparte das vivências de cadaindivíduo e se sobressaino seu comportamento, nos seus métodos detrabalhoenasinterpretaçõesfeitasdarealidadepresenciada. de-sequenãopodehaverfragmentaçãonaidentidadeda pessoa do/a professor/a, visto que o ser humanoé inacabadoe vai seconstruindoaolongodetodaa vida. Existemalgumascaracterísticastípicasdo/aprofessor/a deEducaçãoFísicaqueodiferenciadosdemaisdocentes, portersuaatuaçãobaseadaempressupostosteónicosque abordamaculturadomovimentohumano, permeada poraspectos relevantes docomportamento. Algunsse mesclamcomasdemaisáreasdoconhecimento,outros sedistinguemportratarem dasemoções, traduzidas na 
corporeidade.Acorporeidadetoma-seopontochavede umavisãoantropológica, noque Assmann(1998,p.61) esclarece: "Acorporeidadedeveserainstânciareferencial decritérios paraaeducação, paraa política, paraaeconomiaeinclusiveparaareligião.Ninguémpodeservir aosvaloresespinituaissemencamá-losemvalorescorporais".Justifica-se,assim, aimportânciadaEducaçãoFísicanocontextoeducacional comoáreadomovimento humanoqueabordaaculturacorporal, poistrazemos impressosnanossacorporidadeaculturalocalemundialesomosafetadosporela.

Nessacompetência,aquestãodovínculoéfundamental,e saberestabelecervínculoscomosalunosecolegasprofessorespressupõeaprenderalidarconsigo(relaçãointrapessoal) ecomosoutros(relaçãointerpessoal). Atravésdeestudos feitosemCogniçãoHumana, obtivereferênciaemGardner (2000,p.58) sobreainteligênciaintrapessoal, sugerindo que:" "...envolveacapacidadedeapessoaseconhecer, deter ummodeloindividualdetrabalhoeficiente-incluindoaî osprópriosdesejos,medosecapacidades-edeusarestas informaçõescomeficiênciapararegularaprópriavida". Para estemesmoautor,(1994,p. 185) ainteligência interpessoal: “.... volta-separafora, paraoutrosindivíduos. A capacidadecentral aquiéacapacidadedeobservarefazer distinçãesentreoutrosindivíduose,emparticular,entreseus humores,temperamentos, motivaçãeseintençães".Eissoé constatadonosprofessoresdeEducaçãoFísicapelodinamismoquepossuem, poisdificilmentesevêumprofissionaldacorporeidadeintrovertido.

Osprofessoresconsiderammuitoimportanteconhecer, envolver-secomosalunosesaberdasuavidapessoal,estarpróximodeles, tertratohumano,porentenderemque muitosestãochegandoaumuniversoestranho,ondeirão interagirnoutrarealidade,nãomaisdeadolescentesesim naperspectivadeadultosjovens, comoumitodepassagem. Portanto,receberetratarbemosalunosqueestão chegandoaosbancosuniversitánioséumatarefaprimordialdoprofessoruniversitáio, quevêumbominíciopara conhecerseusalunosnaabordagemdosvaloresdecada um. Osprimeirosvalorestrabalhadosnasturmassãoo conhecimento,ahonestidade, aautonomia, acriticidade earesponsabilidade.Essasqualidadesdenotamascompetênciaspessoaisdacomunidade acadêmica, quevão sendopassadasaosalunos, fundindo-seemvaloressemelhantes, conformeasteoriasqueosprofessoresexercitam. Toma-seimprescindívelaosprofessoresdeEducaçãoFísicasaberouvir,pois os alunossentem-seàvontadepara falar, exporseusanseiospessoais, equantoaoaspectoprofissional,seveeemrefletidosno/aprofessor/a, queaparentementedemonstrapossuirumaliberdadenoexercício dadocênciaqueéumareferênciaimportante.Conforme MosqueraeStöbaus(2001,p.97):

Freqüentemente nos custa muito parar para ouvir os outros, estamos muito mais preocupados em que nos ouçam, porém poucos dispostos a ouvir. Oouvirosoutros e aprender a vê-los como são realmente éfundamental para as relações interpessoais, emespecial para osprofessores, que devem de estarmuito atentos e poder, assim, agirmelhorna realidade.

Entende-se que, para agir melhorna realidade, o/a professor/a universitáriodeveescutaroque os acadêmicospensam, poiselessãoamanifestaçãodosanseios dasuageração,queemalguns aspectos possuimenos preconceitosarespeitodequestões queaanteriorinvestigoueesgotoucomopossibilidadede avançarpara outraetapa. Éimportanterefletirsobreisto, deforma responsável,pelaparticipaçãonaeducaçãocomoum fatordeterminante paraas futuras gerações.Parao/a professor/adeEducação Física, aobservaçãofazparte doconjuntode competências adquiridascomoexercíciodadocência, poisse desenvolveumolharclínico sobreosmovimentos corporais, possibilitandodetectarerros posturaisque, se nãoforem corrigidosatempo, formam caminhos queimpedem os alunos de automatizaremogestocerto, levando-os anãogostarem dos movimentos porerrarem muito.E, falandoseemmovimentos, aautomatizaçãoénecessáriapara queacriatividade seestabeleça. Destacoaquiafalade umaentrevistada: "A qualidade da observaçãopassapor um trabalho dossentidos. Umeducadornão pode sermais aquele observadorimparcial, neutro. Ele tem que atuar e estar consciente que a sua atuação também vai alterar a realidade" (P4). $\mathrm{O}$ espaçofísicodeaçãodo/aprofessor/adeEducaçãoFísicaémuitoamploeé preciso manteros alunos dentrodele, observandoseusmovimentosparaquenãose formemcaminhoserradosnoseu vocabulário motor. 
Assim, conhecerecompreenderasimesmoeaosoutros legitima orespeitoà singularidade doserhumano. Oprofessor, ao prestaratençãonas pessoas, elogiandoseus pequenosprogressoseincentivandoparaque superemosobstáculosencontrados, reforça os êxitos alcançados.Eo/a professor/a deEducaçãoFísicautilizamuitooelogio, poisentendeque faz subiraautoestimae servede estímuloatodos, fazendo-osavançar em seu desenvolvimento motor. No paradigma humanista, que privilegia os sentimentos, afetos, expectativas, interessese valores, bemcomoaempatiae aconfiança, aimportância de conheceroprópriocorpoeodooutro passapeloautoconhecimento corporal, que implica estabelecer uma boa relação coma auto-imageme aauto-estima, conteúdos estreitos da EducaçãoFísica, comopartedodesenvolvimentohumano emuito importante na formação das competências pessoais. A imagem que temos do corpoem determinadas fases dociclo vital podeestar distorcida darealidade,pois nem sempreoqueserefletenasociedadepode estaradequadoatodos. Mosquera(1987, p.52)esclareceque: "Odesenvolvimentodaauto-imagem acontece através de um processo contínuo que estádeterminadopela vidaindividual e que se estrutura naação social". Através doautoconhecimento corporal,pode-secriarestilos próprios condizentescom onível socioeconômicoeculturalemquese vive,construindo uma imagem que se pareça com oideal de determinados biotipos. Isto supõe saberoque proporciona prazer, alegria ou até mesmo a dor.Aimagem corporal própria e a percepção da imagem do outro passapelaemoção, pelaexploraçãodocampovisual. ComoafirmaSchilder(1999,p. 232):“...todaaemoçãomodificaaimagemcorporal.[...]Expandimo-nos, eos limites daimagem corporal perdemsuanitidez". Parainiciaraaprendizagem do conhecimentomuscularearticular, os alunos terão que saberque ocorpo nãoésóaaparênciafísica, equeoconteúdoanátomofisiológicoéinsuficienteparadaroentendimentoglobaldoserhumano, que pensa, tomadecisões, temsentimentos. Osprofessoresentrevistadosentendemque, aoreligar constantemente a anatomia humanacom osentir, consegue-sedarvozaocorpo, que seexpressa atravésdestassensações.

Osentrevistados consideram que atualmente os alunos universitários estãomuitodesatentose, se oprofessornão apresentarde saídauma propostaquelhes chamea atenção, vai ter problemascomaturma, pois elesestãomuitocríticosenãoaceitammais qualquer coisa.Percebe-sepelosdepoimentosque, sermotivador, toma-sefundamental paraoexercíciodocentedaEducaçãoFísicanapós-modemidade.Estemodoativode entenderoensinotorna-se requisito básico paraconseguirointeresse pelaaprendizagemeretroalimentar a motivaçãonoeducador, desejandoquenão se percamjamais o entusiasmo, a alegria e a sensação de bem-estarqueomovimentohumanoproporcionacom aconseqüiente liberaçãodasendorfinas. Nas aulasteóricas, pode-se utilizartemas de relevância social, tais comodrogas, sexualidade, meioambiente, eoutros do interesse dos alunos. Com isso, conseguir-se-á esclarecê-los sobre arealidade dos acontecimentos, revendoconceitosqueestãoforadefoco. As aulasficam com uma alta dose de motivação e os alunos aprendemoqueédoseuinteresse, pois, emnenhuma fase da existênciahumana, se viujovense adolescentes tão descrentes da visão dos adultos. Os padrões motivacionais adequados certamente estabelecerão uma grande diferença entre aulas criativase atraentes, em contraposição às tradicionais. Aolidarcom aspectoscorporais, aprende-se a veroserhumanona sua singularidade, pois ficaevidenteessaposturano professor, de que a sua opiniãoé muito importante, masque ados outros também deve serrespeitada, fatoressemuitoenfatizadoemoutra competênciadesta pesquisa, a profissional.

\section{Competência profissional}

Apretensãodesteestudonãoédescrevertodasascompetências do/a professor/adeEducaçãoFísica esim trazeràs claras algumas que possam apontarcaminhos seguros sobre a suaaçãona pós-modernidade. ParaPerrenoud(2001,p. 139), as competências “... 
englobamossaberes, porémnãoselimitamaeles! Ao contráriodosconhecimentos, quesãorepresentações organizadas darealidadeou domododetransformála, as competências sãocapacidades de ação". Essa categoriaemergiu dos relatos das práticas cotidianas dosprofessores,quenãoéumapráticaindividual,pois éinfluenciada pelas condições de trabalhoe equipe administrativa. Éimportanterefletir sobre aformaçãoemserviço,queestimula os professores a serem produtivosàmedidaque sãomotivadosafazeremno mínimoum cursopor ano, pararepensarseusconceitos, reverumanova abordagem detrabalho, conviver comoutras pessoas, inclusivede outras áreas.

Para que haja mudançano conceito de educação ao longode todaavida, aidéiade educaçãopermanente deveráserrepensadaeampliadanasfaculdades, pois seentendeque, somenteapartirdoestúmulodequem estánocomandodasatividadesacadêmicasépossível que haja uma mudança, do contrário pode levar ao comodismo.Delors(1999,p. 18) sugereque aeducaçãocontinuadadeve “....serencaradacomoumaconstrução contínua dapessoahumana, dosseus saberese aptidões, dasuacapacidade de discernire agir". Nos dias atuaisnãocabeauniversidade ficarfora. Elatem queparticipardessamudança, comprometendo-secom oseuquadrodocenteecomos profissionaisquejáformaramequeestãocomseu conhecimentodefasado. Os professoressãounânimesemafirmarquenecessitamdemaistempoparadedicar-seàs suaspesquisas. Emboraentendamqueestejaminvestindoemseuaperfeiçoamento,elesestãotendoque subtrairestetempo doseu descanso, oqueparticularmentenãoconsidero muitosaudável.

Osentrevistadosrelatamquevivem crisesdecrençae descrença, poisauniversidadeestápresenciandouma situaçãocomplexapelasexigênciasquesãofeitas pela sociedade. Háuma crise dehegemoniaintensaacontecendonasuniversidadeseéconsideradaa mais ampladetodas, portratardosconhecimentosqueproduz e transmite. A crise de legitimidade, faladafalência dos objetivos coletivos assumidos. Eacrise institu- cional,põe em causaaautonomiaeaespecificidade organizacional pelas políticas de financiamentoque estãocada vezmaisrestritivas. Soma-seaissoanecessidadedereveraspectosimportantes que possamabrir novoscaminhosparapossíveis soluções.

Os Parâmetros Curriculares Nacionais, que contemplamopensamentode vários autores, tambémserviramdeapoioteórico paraeste trabalho, porentender aimportânciaqueestedocumentotemparaos profissionaisdaeducação.OdocumentoMEC-PCNs(1999, p.154-5)propõe:
A Educação Físicaprecisabuscar suaidentidade como área de estudo fundamental para a compreensão do ser humano enquanto produtor de cultura. [...] A vi- são legal, quando confrontada com a realidade do en- sino de Educação Física, apresenta-nos um paradoxo: anossa prática pedagógica em pouco tem contribuído para a compreensão dos fundamentos, para o desen- volvimento da habilidade de aprender ou sequerpara aformaçãoética.

Para osparticipantesdestapesquisa, oqueo/aprofessor/adevedominarnestepróximomilênio,nosentido decapacidade,ébasicamentesaberaprender.Emeducação, oensinare o aprender são fundamentos básicos doprocesso em questão, pois visao elaborar do pensamentocomplexo,fazendoligaçõesimportantes e significativas. E para Demo (2000, p. 261) “...o 'aprenderaaprender' supõetambémaprender, mas seucentroestánosaberpensar, fundamentodo sujeito social conscienteecompetente". Essacompetência sugereque sedesenvolvammétodosespecíficos, respeitando-se as individualidades, pois cada pessoa internaliza os gestos ou fatos de uma formaparticular, conformeseusconhecimentosimplícitos. Porvezes, coincide comodogrupo, maso/aprofessor/ade EducaçãoFísica,aodesenvolveressacompetência, sabe queosgestossãoconstruçõesquenecessitamseraprendidas. Assim, a competênciaprofissional que se refere ao aprender a aprender, parece ser amais importante na opinião dos entrevistados, a que formaráa base de todo o conhecimento e que supõe aprenderpara conhecer, exercitando aatenção, ame- 
móriaeopensamento.Assmann(2000,p. 259) sugereque: "Aprenderaaprenderémanteracesaacuriosidade. Omeroensinar, ou meraentrega de saberes supostamente prontos, mataa curiosidade. [...] apagarcuriosidadesédespotenciarneurôniosdocérebro humano".Eo/a professor/a, ao ver despertada sua curiosidade, no sentidode buscar alternativas novas para os problemas que se apresentam no dia-a-dia, nãodeixaqueaulas monótonas tomem conta do seu fazerpedagógico.ParaRestrepo(1998,p.33): “Aprenderésempreaprendercomosoutros, pois asestruturasdepensamentonãosãomaisdoquerelaçõesentre corposque se interiorizaram, afeições que, ao se tornaremestáveis, nosimpõemumcertomodelodefechamentooudeaberturadiantedomundo".O/A professor/adeEducaçãoFísicaaprendesemprecomasua corporeidadeprevendonovas formas deatuação.

EmEducaçãoFísica, acomunicaçãoéumatocriativo entre as pessoas, visto que permite que se dê outras interpretações referentesàcorporeidade. Quandoas pessoas se comunicam formam um sistema de interação e reação integrado, o que para Assmann (1998,p. 134): “... supõequeacompetênciapara comunicar, tambéméconstruídaemfunção daexperiênciaedeuma práticarefletida". Assim, terrecursode linguagem, demovimentos, decomunicaçãoilimitada torna-se uma ferramentaimportante paraum trabalho bem elaborado. Essa competência possui imbricaçãocomadacriatividade ecomocotidiano, faz parte dacultura das pessoas. O/A professor/a de Educação Física atual está mais cooperativo, integrador, persistente, elaborandonovas formas de atuações, preparando-se para atuar nestemilênioe considera que envolveros alunos no planejamento estratégicodas ações conjuntas pode serumpontode equilibrio nas atividades profissionais. A missãode ensinarfuturos professoresdeveserpermeadadedoação, pois istofarádespertar o prazer de ensinar.Arecompensa dodinheiropelotrabalhodesenvolvidoé muito importante, mas se somente isto importarnão haverá doação e, provavelmente as aulas serão
entediantes.Nãohánadamaiscontagianteeprazeroso, do que uma aula onde o/a professor/atranspareçaa paixãoquetem peloquefalaeensina, destasninguém esquece.

Estasexperiênciassomam-senacomposiçãodascompetênciasdo/aprofessorlaque,napós-modemidadevem carregadadeincertezas. Nestecontexto,Morin(2000a, p.102)sugerequeo/adocentedeve “....prepararasmentesparaenfrentar as incertezasquenãoparamde aumentar,levando-asnãosomenteadescobriremahistóriaincertaealeatóriadoUniverso, davida, dahumanidade, mastambém promovendonelas ainteligência estratégicaeaapostaemummundomelhor".'Osentrevistadosapontamafaltadepreparoqueosjovensestãochegandoàuniversidade, osqueconseguemchegar, poisasincertezasqueenfrentampelonúmerodevagas existentes se tornam um obstáculo, por vezes, intransponível.Sobreasincertezas, refere-seumprofessor: "Paramima maior surpresa do currículoéa incerteza, évocê entrar em coisas quenãoestão escritas. Ogrande problemadomundoéteracerteza quetudoéincerto. Euachoque aincertezaéagraçadomundo"(P7).Éprecisodarresponsabilidadeao alunoparaeleirolhandoparafrentee, prepará-lopara asincertezasfaz parte doambienteacadêmico.Dessa forma, oquenãoestáescritosãoosconteúdosocultos quepassampelafilosofiade vidado/aprofessor/aque, quandofaladasemumaturmadealunos transformaseemoutrotipodediscussão, que osmotiva, poiséo momentoemqueaspersonalidadesserevelametentamseadequaraosnovosconhecimentosqueestãose descortinando, basicamenteéondeosalunosconseguem darsignificadoaoqueestãoaprendendo,principalmente quandoos professoressereferemàssuasexperiências profissionaisforadauniversidade, emescolas, clubesou atuações voluntárias. Agora, acettezaou aincertezado campo onde ele vai atuar, estácada vez mais ampla. Morin(2000b, p. 84)falaque umanovaconsciência começaasurgir: "Éprecisoaprenderaenfrentaraincetezajáquevivemosemumaépocademudançasem queos valores sãoambivalentes, emquetudoéligado. 
Éporissoqueaeducaçãodofuturodevese voltarpara asincertezas ligadasaoconhecimento". Estaaventura estáprecisamentenocemedenovas descobertas profissionais, pois não existe nada mais inseguro para a criatividadedo/aprofessor/adoqueasegurançadeuma atuaçãoquenãodesperteneleosentimentodainovação.Osprofessoresandamas voltascomessas mudanças, que estãotirando-lheso sossego, pois sabem que algourgenteprecisaserfeito, oquepodesersentidoatravésdosestudossobreumnovocurrículo. Aincerteza, sendoumacaracterística dapós-modernidade, levaa umamaiorcompreensãodousodaliberdadenasatividadesprofissionais,poisaoromperem-seoslimitescom acerteza, ampliam-seaspossibilidadesdeatuações.Para tanto,napós-modemidadeas pessoasnãomais poderãosefecharnumúnicofazer, e simabrir-seàs oportunidades, tendopresenteque, paracadalocal novode trabalho, deverãoestarpredispostasaaprenderaaprender,oquedeveráserfeitosempre.ParaMorin(2000a,p. 126), "Aliberdadesupõe,aomesmotempo, acapacidadecerebral ouintelectualdeconceberefazerescolhas,e apossibilidade deoperaressasescolhas dentrodomeio exterior.[...] Osujeitopode, eventualmente, disporde liberdadeeexercerliberdades".

Na aquisição da competência profissional na pósmodemidade,éimportante ter-seemmentequenão se educa apenas para o momento esim para todaa vida. Paraos participantes, saberatuarna perspectiva interdisciplinaréumacompetênciaprofissional nova, pois namodemidadeoindividualismo prevaleceu. Os docentesentendemque devemseimbuirdeumcompromissoque os leve a procurarnovas formas deatuação, bem como estar ligados aocotidianodos acontecimentos, trazendo-os paradiscussãojuntoaoscolegas, comoressaltaumprofessor:

Oprofessorde Educação Física na pós-modernidade deve ser competente sabendo atuar interdisciplinarmente, sendoflexível, empático e penso que não existammuitos profissionais comesseperfil. O ser humano estánamão do professor, as academias estão cheias de pessoas quefazemoquenós dissermos, atéabsurdosse foremmandados por um profissional da Educação Fí- sica; a terceira idade estánas nossas mãos. Agora se não tiver competência profissional põe tudo a perder, não vai ser um bom profissional (p. 8).

Os participantesdeste estudo consideramqueparaser umbomprofissional,sedeveexercitarconstantemente “... a competência da auto-avaliação, que éfundamental tantono aspecto profissional, quantonopessoal" (p. 10). Afirmam que devem submeter-se à autocríticadassuas experiências profissionaisparaque possamcompreendersuas práticas pedagógicas, oque segundoMorin(2000b,p. 100)estapráticapermanente é “...necessária, já quea compreensãodenossas fraquezas oufaltaséa viaparaacompreensãodasdooutro.Sedescobrimosquesomostodosseresfalíveis, frágeis,insuficientes, carentes, entãopodemosdescobrirque todosnecessitamosdemútuacompreensão". Eapósmodernidadecomportaeste desvelardasinsuficiências humanas, quesobaóticadacompetênciasocial, trata daspesquisasfeitascomasociedade, dando-lhevozpara quesefaçamouvirseusapelos através deestudosrelevantesecondizentescomumapráticaexercida, queuna ateoriaembenefíciodestasociedade.

\section{Competência social}

Nacompetênciasocial,o/a professor/adeEducação Física busca participar das transformações da sociedade,formarcidadãos conscienteseresponsáveis, utilizandoseusconhecimentos paramudar a sociedade aoseuredor, respeitando aculturados povosecontribuindoparaodesenvolvimentoplenodoserhumano. ComaEducaçãoFísica, colocadaa serviçodacomunidade, vê-se grandes possibilidades de conseguir o intentode uma sociedade supostamente mais justa, vistoserumadisciplinaqueprimapelasociabilização, conseguidaatravés dolúdico, oqueimplicasolidariedadeecooperação.

Nosambienteseducacionais, olúdico(termolatinoque designao brincar) favorece a aprendizagem, noque Santin(1987,p. 82)esclarece: “.... aprendemosadefinir ohomempelasuaracionalidade. Masnãoseriapossíveldefinirohomempelasualudicidade?Temosassim 
oHomoludens". Paratanto,faz-senecessárioadquirir acompetênciasocial de aprendera cooperar, ajogar comosoutros, acompartilhar, amudaralgumasregras nojogoadaptandoparaquetodosjoguem, oquepara Delors (1999, p. 15) se faz “...de modoaconciliara competiçãoqueestimula, acooperaçãoquereforçaea solidariedadequeune". Osentrevistados relatamque temumgnupodeprofissionaisquenegaacompetição, maselesnãonegam, estimulamefomentamjuntocom acooperação.Comoressaltaumparticipante: "Nóscompetimosecooperamos, afinal nãochegamosatéaqui de graça" $(P 2)$. Deve-setrabalharsobre vitóriasederrotas,comomeiodeeducarparavivernestemundo,pois oserhumanocompetedesdeaconcepção.Efalando-se emEducaçãoFísica, as situações proporcionadas nas aulasreproduzemascondiçōes sociaisdoindivíduonos seuslocaisdeatuaçãofuturas. Assmann(2000,p.218) esclarece: "Éprecisodaraosjovensocasiõesdeparticiparematividadesfísicaselúdicasagradáveisenãocompetitivasparaqueocomportamentosocial positivo,[...] nãoseconcentreexclusivamente, nemprioritariamente naformaçãodeumagressivoânimodecompetitividade mercadológica".

Estaformaagradáveldeserelacionarsocialmentefará comqueas crianças dehoje,transforme-seemadultos tranquiilosamanhã. Nãopodemosperderdevistaaimportânciadistoparaaeducação, poisninguémeduca sóparaomomento,istovaiterrepercussãoemtodasas esferassociais. Assim, atravésdaobservaçãodecomoos alunosagemnasociedadeescolar,pode-sediagnosticar futuros problemas derelacionamentos, quepodemser tratadoscomauxiliodacomunidadeeducacionale dos pais.Porisso, aEducação Físicadesempenhanasociedade uma funçãoimportante, que demanda uma competência social que saia do plano dojogopelo jogo e assuma um compromisso coma comunidade. Afinal oconhecimentoadquiridonafaculdadesobrehigiene, cuidadoscomocorpo, saúdee primeiros socomos, atendimentosimediatos, ampliamocomprometimentosocialeresponsabilidadedo/aprofessor/ade EducaçãoFísicaperanteapopulação.
O/Aprofessor/adeEducaçãoFísicatemmuitascompetênciaseeletemquecumpri-las paraqueasociedade possaenxergarnele/aoprofissionalqueelaespera.Estãoquestionandomuitoopapeldo/aprofessor/anaescolaenasociedade.DeacordocomDelors(1999,p.18), o/aprofessor/adeve:"Tomarconsciênciadesipróprioe domeioambientequeorodeia, eadesempenharopapel social que lhe cabe enquanto trabalhadore cidadão". Na sociedade atual, estáhavendoumaabertura aoconhecimento, construídoapartirde experiências adquiridasedeestudoselaborados. Comoshipertextos disponíveisnaintemet, estãosepopularizandoasinformações, assimnãocabemaisaposturadeesconderou daracesso aumaminoria, dos saberes produzidosna universidade. Tambémseencontram váriasorientações decuidadoscomasaúdedocorpo,defácilentendimento,equenãochegaarepresentarumacompetiçãopara osprofissionaisdaEducaçãoFísica, poissabemos, atravésdosestudosfeitos,quenapós-modemidadehálugar paratodos atuarem, nosmaisdiversos locais. Osprofessoresseencontram preocupadoscomasquestõessociaisecoma posturaéticae sugerem trabalhar com as diferençaseos desafios derespeitar, de aprenderasere deaprenderaconviver.

Dosprofessoresuniversitáiosasociedadeesperaumtipo de comportamentoestabelecidocomopadrãoeoseu statussocial temumaaltadosedeboaconvivialidadee, que,tambémnasociedadeeducacional, saibamperceberasintençõesdooutrosemjulgamentoprévio,como intuitodecompartilhar,comodizDelors(1999, p. 19): "Trata-sedeaprendera viverjuntos, desenvolvendoo conhecimentoacercadosoutros, dasuahistória, tradiçõeseespiritualidade.[...]Utopiapensarãoalguns,mas utopianecessária, utopia vital parasairdocicloperigosoquesealimentadocinismoedaresignação".'E, aprenderaser sociável supõefazerusoadequadoeprazeroso doseutempolivre,comoumconviteparapraticarum esporte, umacaminhadanumintervalo, assistiraum jogoouatémesmoumaparceriaparaescreverartigose livros, significandorelacionamentossaudáveisdentroe foradoespaçoacadêmico. 
Nomomento,aEducaçãoFísicapassaaterumpapel muitomaisimportante, relacionadoaouso dotempo livre.Parapoderentender oqueaconteceemtermos delazernasociedade atuale compreenderaconstruçãohistórica desselazer,háque se trazerà discussão essetemamovendo-senele. Enquantoconcepçãode EducaçãoFísica, osparticipantesentendemqueaqualidadede vida, queétão comentada atualmente, “... passapelamudançade hábitos no que diz respeito à prática de atividades fisicas e aspectos da saúde comoalimentação adequadae lazer" (P4). Nesse sentido,acompetênciasocial baseadanas produções científicaseencontra, em grande parte, voltadaparaa sociedade, vistas aquicomopesquisassociaise começama aflorar naturalmente, poisnada melhor para umpesquisador do que circularnos ambientes naturais, principalmente os quese dedicamainvestigaros problemassociais.

Acompetênciasocial,nesteestudo,mostrouumaligaçãodiretacomostrabalhose projetos de pesquisas desenvolvidospelosprofessoresuniversitáriosnaáreasocial,bemcomoasinserçõesdosextensionistasnasociedadeesuaconsequientedevoluçãoembenefíciodamesma,compublicaçõesdosresultadosnumalinguagem acessível aosqueseinteressampelos assuntosabordados.Essesresultadossãoevidenciadosemlivros, artigos dejomaiserevistas, naintemet, entreoutros, comouma forma de comprometimento com a comunidade investigada. Heller(1998,p.201), aoreferir-sesobreo pós-modemismo, dizqueomesmoestásendoumaonda cultural que comportatodos ostipos demovimentosartísticos, políticose culturais, ilustrandoque: “...já houvemovimentoscentradosnasaúde, antitabagismo, formafísica, medicinaaltemativa, comidademaratona ejogging". Osprofessoresentrevistadosressaltamaimportânciaquetaismovimentosadquiremparaahumanidade, além disso,estãoconscientes dequeapreparaçãocomoscuidados básicos, comoaformaçãodehábitossaudáveisdealimentaçãoede práticas diárias de atividadesfísicasapropriadas,tambémsãode suaresponsabilidadenocontextoeducacional.
Paramelhorentenderosurgimentodopós-modernismocomoteoria social, háque seentender ageração cultural anterior - da alienação, cuja experiência formativadaprosperidadeeconômicadopós-guerrae aabertura das possibilidades sociais teve granderesponsabilidade sobre seu surgimentoem meados de sessentaeoito.Istose deudevidoàdesilusãocausada pelasquestõesqueasegundaondadomovimentocultural trouxeàtona, poissegundoHeller(1998,p.200), a civilizaçãoestava "... desiludida com sua própria percepçãodomundo". Paraestaautora:

Esses movimentos foram saturando cada vez mais as relações humanas com suamensagem, em talmedida que alteraramotecido social do qual haviam surgido. Opós-modernismo comomovimento cultural (nãoideologia, teoria ou programa) tem uma mensagem bastante simples: vale tudo.

Umdestes movimentos culturais lançadosnaépoca daalienaçãoocasionounaeducaçãoumexcessode permissividade, coincidindocoma vindadoEsporte para Todos que chegava ao Brasil para controlaros ânimosdaNação,comasigladeEPT.Essemovimentochegourápidodemaisenãohouve umapreparaçãopréviateóricadosprofessores, oque deixouaberto a váriasinterpretaçõesempíricas.Porém, eleabriutrilhas na percepção da civilização que antevia uma massificaçãodoesporte, comumavertentemuitoforte para a recreação. Neste momento, nota-se quea temáticadascompetênciasjáestavasendoevidenciadaetomava-seurgenteadquirirnovashabilidadespara desenvolveroutrasformasdeensinaraEducaçãoFísica. A prática pedagógica estava se afastando do tecnicismoeasnovashabilidades, ao serem aprimoradas pelaexperiênciae estudo, transformar-se-iam nessasnovascompetências.

SegundoAssmann(2000,p.217)éimportanteperdero medoaconceitosquesereferemexplicitamenteàcompetência: "Oapeloàsolidariedadesóatingeavidacotidianadaspessoasquandoérelacionadocom transformaçõesconcretasepossíveisdoscomportamentossociaisemqueelas seencontram. Oserhumanoéumser derelaçõessociaisconcretasenãoumsujeitoreceptivo 
paramensagensquepoucotêmavercomelas". Assim sendo,historicamenteos professoresdeEducaçãoFísica sempreforam vistos comoos profissionaisque, dentro dos espaços queinteragem, sãoos responsáveis pela sociabilizaçãodas pessoas. Aimportânciacomoeducador/asocial sefazsentirem vários locaisondeas outras licenciaturasnãotêmacessotaiscomo: os ginásios de esportes, as academias, os clubes, as clínicas, entreoutros.EnaEducaçãoFísicaareceptividadee atransmissãodeinformações, atravésdosmovimentos-gestos de corpos, tendemaacontecerdemaneiranaturale espontânea, sucedendo-se um elo de ligação unido pela interdependência. Segundoos professoresquecolaboraramcomesteestudo, educarparaacompreensãoentreaspessoas, dizrespeitoàsolidariedadehumana. $\mathrm{Na}$ EducaçãoFísica,esteéumvalorassociadoaomovimento pós-modemo,ondenãocabemais aposturadovencer aqualquercusto. Sersolidárioimplicaverooutroapartir desipróprio, masparaissoénecessáriomudarofoco dosrelacionamentos.Éconsensoentreosprofessoresque aqualidadepolíticaestámais fortee determinantenos papéisdesempenhadosatualmentenaEducaçãoFísica. Demo(2000b, p. 18)dizque:“"...pode-setrabalhara solidariedade eaética políticademaneiramaisobjetiva, lançando sobre oconhecimentoodesafiodaqualidadepolítica".Paraentenderoqueestáacontecendo nomundoéprecisoaprimoraressacompetênciapolítica, legitimandoalgumas coisascomos alunosecolegas, sejacompetiçãooumovimentosocialquetrazembutidoaquestãoética.

Acompetênciaéticatambémsetraduznasaçõesdossujeitosqueatuamnas realidades próprias, aqui denominadasporestágios, comoserefere umaprofessora: " $\mathrm{OS}$ alunos quando saempara os estágios agem de uma forma, quando retornamà faculdade agem de outra" (P10).Paraessesalunos, aatuaçãonasociedadeos faztercomportamentosdiferenciados, aindaprevalecendoodualismo.Assmann(2000,p.210)consideraque:" A educaçãoprecisateracoragemdesuperarodualismo persistenteentreformaçãoparaobomdesempenhoprofissional,eissonumaeradeprofundatransformaçãodo próprioconceitodetrabalho,eformaçãoética paraaso- ciabilidadehumana". Algunsalunos,paraconseguiralgumfavorecimento, passam porcimadecertos valores prejudicandoseuscolegaseissoestáacontecendoatodo instante.Comoressaltaaparticipante: "Umadasfalhas daeducaçãoéaquestãoética. Senóstivéssemosuma postura ética, quantoàs regras de conduta dos alunos(freqüiencia outras), maisoumenos semelhante muita coisa poderia ser evitada"(P10). Paraos/as docentesdainstituiçãopública, as açõesdos professores namesmainstituiçãosãomuitoindividuais. Seniaapropriadoseguiralgumasregrasdecondutaquealinhassem ofazerdosprofessores, principalmentenasquestõesburocráticas.Bauman(1997,p.25)dizque: "Nossasferramentaséticas-ocódigodecompoitamentomoral,oconjuntodasnormassimplesepráticasqueseguimos-simplesmentenãoforamfeitosàmedidadospoderesqueatualmentepossuímos'. Reveroquenãoestábomparaos ambienteseducacionaispareceserpossível,bastaquese tenhavontade políticaparaorganizaresteespaçofísico. Assmann(1998,p.113)falaarespeitodaéticanoconvíviosocial:

Ocerne ético, antropológico e políticodo conhecimento, ou seja, a radicalidade democrática e a inclinação a soluções pacífica dos conflitos que surgemno convívio social humano, são dimensões do conhecimento que precisam sercriadasno interiordosprocessos de aprendizagem. Emtermosmais tradicionais, trata-se daformação humana e política dos cidadãos.

Osdocentesconsideramimportante trazerproblematizaçõesinstigantesnabuscadeefetivarapromoçãodesujeitossociais,naformaçãohumanaepolíticadosalunos enãosóorepassedeconhecimentosreferentesàcultura corporal.Morin(2000a,p. 82) consideracomo valores intrínsecos àculturauniversitária, "....aautonomiada consciência, aproblematização(comaconsequiênciade queapesquisadevesersempreabertaeplural)eoprimadodaverdadesobreautilidadeeaéticadoconhecimento". Osaspectosrelevantesdesteestudonosremetemao comprometimentocomasociedadeeducacional, deformaquetodasaspessoassecomprometamcomasfuturas gerações, reorganizandooespaçoem volta, paraqueo princípiodaunicidadepossaprevalecer. 


\section{Conclusão}

Estetrabalhosepreocupouem analisar, através dedepoimentos, as competências que o/a professor/a de EducaçãoFísicanapós-modemidadedevepossuir.As competênciasestãopassandopormudanças, pornovasrepresentaçõesenovasqualificações visandoatenderum novo cidadão, mais livre, com seus valorese crenças próprios. Essasnovascompetênciasseintegram pormetas comuns, onde os valores de solidariedade transcendemo vencer, easnecessidades humanas se colocamacimadacompetição.Dessaforma, aspessoastendemanãomais se fecharemnoparticulare sim conceberem os conjuntos, os grupos, favorecendoo sensodaresponsabilidadeedacidadania. O/A professor/adeEducaçãoFísicadoséculoXXIdevepossuir umconhecimentoaprofundadododesenvolvimento humano, passandoporquestõesquefalam doscuidadoseprevençõesqueascompetências prevêem. Deve sabertambémqueoafetoéumdiferencial de vidapsíquica, gerandobons relacionamentos, conjugandoa sensibilidadeparaperceberooutroeasimesmonuma interaçãocomomundo.

Nacompetênciapessoal, deve-sepossuiracapacidade deestabelecervínculos, bemcomosaberobservareelogiaros pequenosêxitos. Possuirempatia, esabercomunicaroque se quercom clareza. Osedentarismo queestáocorrendohoje levaoindivíduoasermenos produtivonas suasatividadeseaperdergradativamente suas formas harmônicas. Assim, é precisobuscaro autoconhecimento, poisconhecer-se tambémsignificasaberouvir seu corpo, daroque ele precisanomomento adequado, seja alimento, carinho, higiene ou movimento. Sentir sua pulsação, saber quandoestá executandoa digestão, quandonecessitade sono, ou simplesmentede descanso, aprenderase exercitarea relaxar.

Acompetênciaprofissionalapontouumasériedeações queo/aprofessor/adeEducaçãoFísicapós-moderno devepossuirparatransformararealidade.E, ressaltou que as universidades encontram-se em ruptura epistemológica,enunciada porcrises eincertezas, características dapós-modernidade, eos professores vivemestemomentocaóticopeloqual passaaeducação atualmente. Aindaexisteacom-partimentaçãodas disciplinas e os exercícios inter-disciplinar e multidisciplinarsãovistoscomoaçõesisoladas. Assim, pensam que o conhecimento básico deve ser aprofundadoparaalém dauniversidade, ondeos professorespossambuscá-losemprequehouvernecessidade através da capacitação permanente, utilizado comoumrecursoconstantenestaera.

A competênciasocial estápermeadapelas pesquisas feitascomasociedade, ondeosprofessores vêemapossibilidadeconcretade atuarem comoeducadores sociaisfazendoum trabalhoduplo. Aosairdoespaçouniversitárioparaarealidade,comopropósitodeinvestigaros problemas sociais, dopontode vistadaEducaçãoFísica, estudampossíveis soluçõesquepossamser configuradasemsaberesúteisà sociedade.Mesmoque este processonãoaconteçanaturalmente, pode-se dizerque os professores nãoutilizamadequadamente todas as suas competências, mas sabem quais sãoe queaspossuem.

Visualizandoumametáfora, vejoafaculdadeprivada comoumalanchamuitogrande, linda, nova, comtripulantes jovens, cheiosdeentusiasmopelaaventura deensinarumanova visão de corpo, mundoe sociedade.Queosventos sopremsempreaseufavor,enão sepercamnuncaosideais. A realidadeestápostaeindicafalha. Écomoum grandenavio, forte, imponente, queapresenta vários danosnoseu casco, exigindo alguns reparos urgentes. Penso que com a pósmodernidade,échegadaahora detodos participarem deummutirãoparaconsertaressenavio, pintá-locom cores vibrantes, trabalhar unidos, com muitoritmo, movimentos sincronizados, alegria, leveza, respirandooardas inovações. Essenavioésimbolizadopela faculdadepública. 


\section{Referências}

ASSMANN,Hugo.Reencantaraeducação:rumoàsociedade aprendente.Petrópolis: Vozes, 1998.

ASSMANN,Hugo;SUNG,JungMo.Competênciaesensibilidade solidária: educarparaaesperança. Petrópolis: Vozes, 2000.

BRASIL.MinistériodaEducação.SecretariadeEducaçãoMédia eTecnológica. Parâmetros Curriculares Nacionais: ensino médio.Brasilia: MinistériodaEducação, 1999.

BAUMAN,Zygmunt.Éticapós-modema.SãoPaulo:Paulus,1997.

BAUMAN,Zygmunt.Omal-estardapós-modernidade. Riode Janeiro:JorgeZahar, 1998.

DELORS, Jacques etal. Educação: umtesouroadescobrir.RelatórioparaUNESCOdaComissãoInternacional sobreEducaçãoparaoséculoXXI.3.ed. SãoPaulo:Cortez, 1999.

DEMO,Pedro.Educarpelapesquisa. 4.ed.Campinas: Autores Associados, $2000 \mathrm{~b}$.

DOLLJr.,WilliamE. Currículo:umaperspectivapós-modema PortoAlegre:ArtesMédicas, 1997.

GARDNER,Howard. Estruturas damente: A teoriadaInteligênciasMúltiplas.PortoAlegre: ArtesMédicas, 1994.

GARDNER,Howard.Inteligência: umconceitoreformulado.Rio deJaneiro: Objetiva, 2000.

HELLER,Agnes.Acondiçãopolíticapós-moderna. RiodeJaneiro: CivilizaçãoBrasileira, 1998.
MORIN,Edgar.Acabeçabem-feita: repensarareforma, reformaropensamento. Riode Janeiro: BertrandBrasil, 2000a.

MORIN,Edgar.Ossetesaberesnecessáriosàeducaçãodofuturo. SãoPaulo:Cortez;Brasilia:UNESCO,2000b.

MOSQUERA,JuanJoséMouniño.Oprofessor,personalidadesaudávelerelaçõesinterpessoais: porumaeducaçãodaafetividade. In:ENRICONE,Délcia,(Org.). Serprofessor. PortoAlegre: EDIPUCRS,2001.

MOSQUERA,JuanJoséMouriño.Vidaadulta: personalidadee desenvolvimento.3.ed.PortoAlegre:Sulina, 1987.

PERRENOUD, Philippe. Ensinar: agirnaurgência, decidirna incerteza.PortoAlegre:Artmed,2001.

SANTIN,Silvino. Educação Física: umaabordagemfilosófica dacorporeidade.Ijuí:UNIJUÍ, 1987.

SCHILDER,Paul.Aimagemdocorpo: asenergiasconstrutivas dapsique.3.ed. SãoPaulo:MartinsFontes, 1999.

RESTREPO,Luis Carlos.Odireitoàtermura. Petrópolis:Vozes, 1998.

\section{Notas}

* MestreemEducaçãopelaPontifíciaUniversidadeFederal doRioGrandedoSul

Recebidoem:09/08/02

Aceitoem: 11/11/02 
